\title{
Typical Production Curve Types and its Geological Meaning of CBM Wells in Fanzhuang Block, China
}

\author{
Mengxi LI ${ }^{1, a}$, Jun TANG ${ }^{* 2, b}$, Zhouqi CUI ${ }^{1, c}$, Shuaishuai LIU ${ }^{2}$, \\ Yanjun $\mathrm{CHEN}^{1}{ }^{1}$, Wei $\mathrm{YU}^{1}$,
}

\author{
${ }^{1}$ PetroChina Huabei Oilfield Company, Exploration and Development Research Institute, Renqiu \\ 062552, China;
}

${ }^{2}$ Key Laboratory of Coalbed Methane Resources and Reservoir Formation (Ministry of Education of China), China University of Mining and Technology (CUMT), Xuzhou, Jiangsu 221008, China

a15162145825@163.com, b18252431216@163.com, c13852106610@163.com

\begin{abstract}
Keywords: CBM; Production curve; casing pressure; inter-well interference
Abstract. Based on reservoir characteristics and production curves of 49 CBM wells in Fanzhuang block, the production curves were divided into five types: single-peak type, double-peak type, step type, linear type, triple-peak type. According to geological factors such as CBM content, permeability and engineering factors like daily water production, casing pressure lowering depth in prior period, inter-well distance, the formation mechanism of 5 types of production curves were analyzed. Research suggests that daily CBM production has a positive correlation with CBM content and permeability. In contexts that inter-well distance is similar to daily water production, fast rate of decline of casing pressure will cause CBM production peak in the short term, production curves of poor reservoir physical property tend to single-peak type, production curves of good reservoir physical property tend to double-peak type; slow rate of decline of casing pressure will cause low production in initial period, and CBM production rising steadily with the gradual decreases of casing pressure, production curves of good reservoir physical property tend to step type, production curves of poor reservoir physical property tend to linear type; the forming reasons for triple-peak type mainly are gas supply of descending CBM wells around, good coal reservoir property (high CBM content, high permeability) and inter-well interference.
\end{abstract}

\section{Introduction}

In the process of CBM exploration and development, a large amount of research has been done by relevant researches. Geological factors affecting production of CBM wells includes: resources abundance, gas saturation(Ni et al., 2010), coal texture(Ni et al., 2010), structure(Wang et al., 2014), permeability(Ni et al., 2009), buried depth(Yang et al.,2008) and so on; engineering factors affecting production of CBM wells includes: well drilling, well cementation and well completion(Chen et al., 2006), the use of fracturing fluid(Chen et al., 2006), working system of drainage in later stage(Zhang et al.,2014) and so on; Tao et al.(2014) take Fanzhuang block as example, and concluded that the critical reservoir ratio, liquid column height, gas content are the main influencing factors in determining well productivity; Aimed at engineering factors, researches made up reasonable drainage system from a perspective of production curve, then guides the production. Production curve is dynamic display of production characteristics, which contains flowing bottom hole pressure, dynamic fluid depth, daily gas production, daily water production, casing pressure, pumping speed and so on. Kang et al. summarized 8 typical dynamic indexes based on production curves of CBM wells, and analyzed the relationship among typical indexes, geological factors and engineering factors; production curve types were divided according to dynamic changes of CBM wells during gas rercovery(Yang et al., 2008; Luo et al., 2012; Hu et al., 2012). Through studying production curve characteristics of CBM wells in Fanzhuang block, this paper introduces the coupling effects between different dynamic indexes, then reveals the relationship between production curve types and internal geological factors. 


\section{Regional Overview of Fanzhuang Block}

Fanzhuang block located in a slope of southeast Qinshui basin, which is typical high-rank CBM field. In recent years, this region has always been key areas for CBM exploration, development and utilization. Since Carboniferous-Permian, it formed fault strike and axis of folds, and both of them presents as NNE trending, northern and east-central of Fanzhuang block is well developed structures area; the total gas-bearing area is $398.23 \mathrm{~km}^{2}$ and total CBM resources 104.3 billion m , proven CBM reserves is 35.226 billion $\mathrm{m}^{3}$. CBM reservoir of No.3 coal seam is the main exploration formation( $\mathrm{Li}$ et al., 2012). The thickness of No. 3 coal seam is range from $2.35 \mathrm{~m}$ to $8.85 \mathrm{~m}$ and mostly about $6 \mathrm{~m}$. the simple coal structure and stable distribution being evaluated as main minable coal seam. The effective porosity of No.3 coal seam is from $2.05 \%$ to $7.09 \%$, and the average value is $4.23 \%$. the mid-value semidiameter of pore is ranged from $0.0353 \mu \mathrm{m}$ to $90.65 \mu \mathrm{m}$, and the average value is $38.151 \mu \mathrm{m}$. Generally, No.3 coal seam developed 2 groups of nearly orthogonal fractures, the reservoir pressure of No.3 coal seam is $3.49 \mathrm{MPa}$, which is coincide with Qinshui basin, namely, abnormal low pressure. The gas content ranges from $11.16 \mathrm{~m}^{3} / \mathrm{t}$ to 22.14 $\mathrm{m}^{3} / \mathrm{t}$ (air dry basis) and the average value is $18.97 \mathrm{~m}^{3} / \mathrm{t}$, the gas content increases from south to north. So far there are over $1100 \mathrm{CBM}$ development wells and produces about 0.57 billion $\mathrm{m}^{3}$ annually.

\section{Research Methods}

In this paper, drainage data of $49 \mathrm{CBM}$ wells in Fanzhuang block were selected to be researched. The location of CBM wells were shown in figure1. The well selection principle is:1) the distribution of CBM wells maximum cover the region; 2) select vertical wells and part of cluster wells as study objects; 3) analyze the same coal seam; 4) select longer drainage well. The average gas production time of $49 \mathrm{CBM}$ wells is 1728 days and the average daily gas production is $1424 \mathrm{~m}^{3} / \mathrm{d}$.

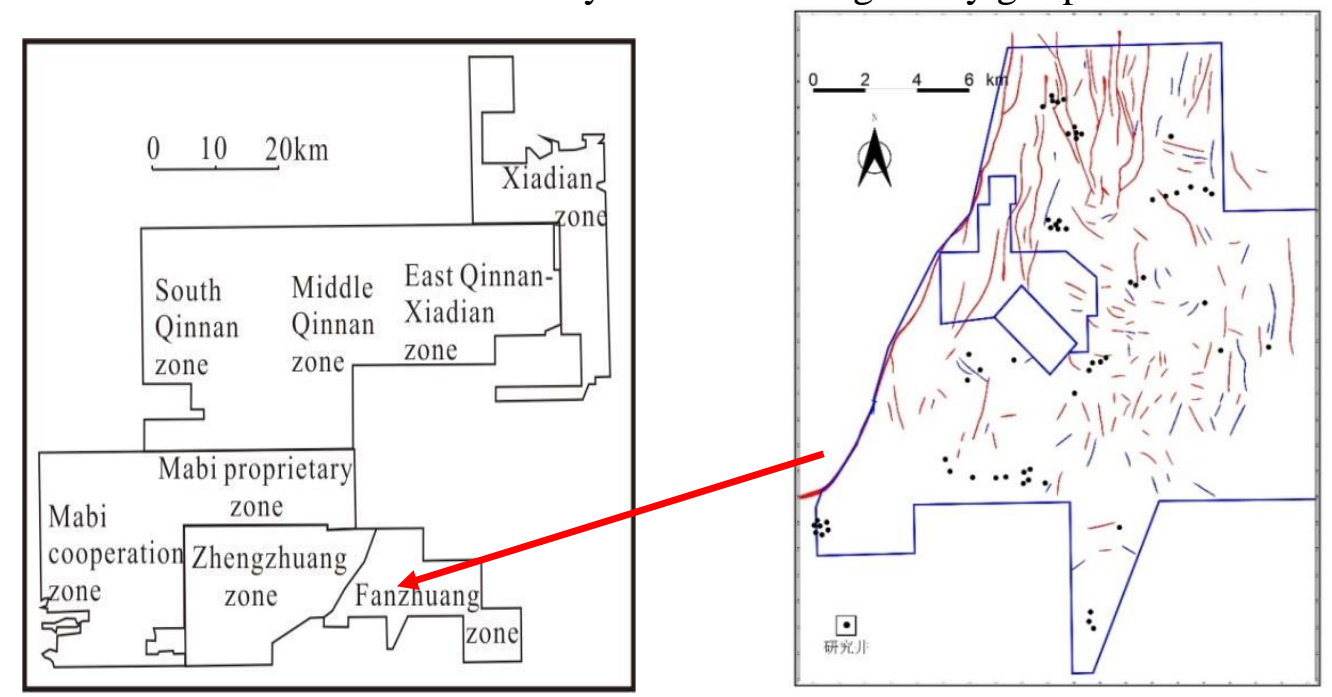

Fig.1 Study well location map

The production curves can be divided into 4 types: single-peak type, double-peak type, step type, linear type (Hu et al., 2012), and the division of the four types based on daily gas production and casing pressure. This paper not only considering the daily gas production and casing pressure, also the inter-well distance and characteristics of water production. In the process of CBM wells production, excessive water production will cause sand and coal powder spouting, then cause reservoir damage and blocking gas transport pathway, eventually reduce production capacity; low water yield will cause slow expansion of pressure drop funnel and longer production period. Short spacing of CBM wells will cause inter-well interference and form a large pressure drop funnel, it is conductive to the increasing of CBM production. Therefore, it is important to study water production characteristics and inter-well distance. 


\section{Typical Production Curve}

The production curve is composed of several dynamic indexes in the process of production, it provide a direct-viewing way to know dynamic changes of gas production while contribute to yield increase. What's more, CBM production can be predicted associate with simulation of software.

Single-peak Curve. The characteristic of single-peak curve is that only appear once stable gas production peak, and the peak generally occurs within 1 to 2 years, the reason is that pressure decrease leads to a great number of CBM desorption. Pressure drop funnel cannot get good extension for failing to reasonable control the relationship between flowing bottom hole pressure and casing pressure, then CBM depression heavily near borehole zones, together with lack gas supplement in the distance, finally gas production shown a sharp decline. After analysis on drainage data of existing CBM wells, the decline rate of casing pressure were all greater than $0.005 \mathrm{MPa} / \mathrm{d}$ before peaks of gas generating in single-peak curves, and the decline rate of casing pressure can achieve to $0.04 \mathrm{MPa} / \mathrm{d}$ in several wells. This type of CBM wells characterized by low water yield, and daily water production is $1.65 \mathrm{~m}^{3} / \mathrm{d}$. The daily water production decreases after gas-generation peak, and it cannot improve the water yield in any pressure. This reflects poor reservoir physical property and low permeability in these region, thus resulting expanding slowly of pressure drop funnel and gas cannot be supplemented timely, eventually lead to a decreasing tendency.

Out of 49 CBM wells polled, type of single-peak curve account for about $26.5 \%$. These wells mainly distributed in northern of Fanzhuang block, the complex structure is unfavourable to accumulations of CBM. In addition, the communication among well patterns were destroyed by low gas content and the development of structure to some extent. The daily gas content of all CBM wells of this type were lower than $1500 \mathrm{~m}^{3} / \mathrm{d}$, and it don't belong to high-yield region.

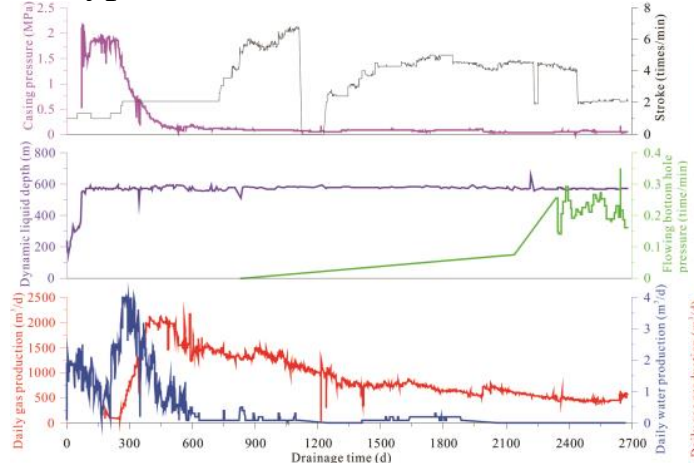

Fig.2 Typical "single peak" curve

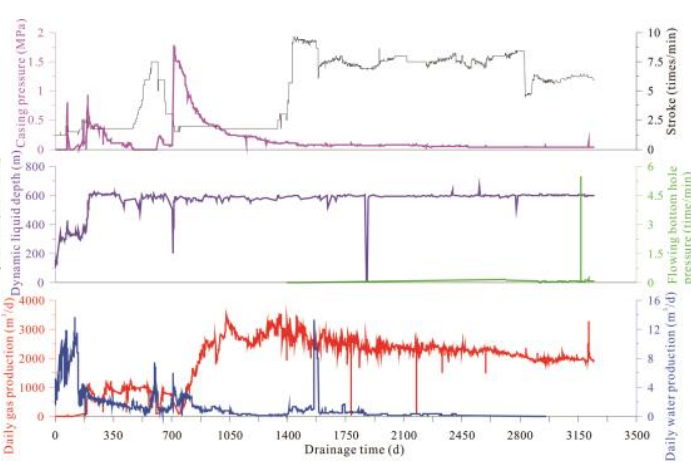

Fig.3 Typical "Stepped" curve

Stage Curve. At the early stage of CBM drainage, type of stage curve shows low gas yield, it presents step increase over time, eventually reach stable production stage and persist for a comparatively long time. The reason for slow growth of daily gas production in initial time is that decreasing speed of casing pressure were controlled, which lead to the rate of desorption and migration be controlled effectively. Then, a great number of CBM were desorbed within drainage radius when the pressure achieve to lower level, and coal matrix shrinking effect become the principle factor, By the time decreased the casing pressure in a phased manner, and drainage gas in a large scale, finally enter the stage of stable production, that's contributes to the phenomenon of stepwise increase. This drainage manner can be summarized as control pressure to produce gas phase,

In stage curve, the first phase is stage period and it will last within 800 days. During the period, the casing pressure decreased gradually, with a speed of $0.002 \mathrm{MPa} / \mathrm{d}$, and the gas production increased significantly; the second phase is stable period, which can last over 3 years, and gas yield remain high level as well as stable gradually, the average daily gas yield is $2000 \mathrm{~m}^{3} / \mathrm{d}$ and daily water yield is $3.03 \mathrm{~m}^{3} / \mathrm{d}$; after stable gas production stage, CBM wells comes in to declining period, the gas yield descend gradually until stop.

With $49 \mathrm{CBM}$ wells counted, stage curve constitute $42.9 \%$. the CBM wells mainly distributed in southern region, with the characteristics of high gas content, short distance of well pattern and perfect physical properties. Stage curve is belong to one of the typical drainage curve of high yield. 
Double-peak Curve. In double-peak curve(Fig. 4), there were two obvious and enduring peaks in the process of gas production, and gas yield in second peak is higher than first gas yield. Combined with the characters of coal reservoir, double-peak curve is an ideal production curve in high-rank coal. The casing pressure and bottom hole pressure decreased rapidly in early stage, which causes reservoir near the wellbore desorbed rapidly, gas production gone up steadily and achieved first peak for fail to control the speed of pressure drop. With the continued desorption, migration and production, CBM near wellbore area have almost exhausted and the primary permeability of distant coal reservoir play an important role, thus the rate of desorption and migration decreases gradually, the daily gas production of CBM wells decreases accordingly. After going through a period of low gas yield, the effect of pressure drop become dominates factors, CBM in distant coal reservoir start desorbed heavily and migration and came into its second peak.

From an engineering perspective, the reason for double-peak curve can be explained in distance between wells and decreasing rate of casing pressure during peak periods. Since the second gas production peak is caused by regional pressure drop, the choice of distance between wells is very important. From statistical data of 49 CBM wells, the average distance between wells is $213.33 \mathrm{~m}$, and production CBM wells around distributed uniformly, the whole drainage area is relatively large. Considering from casing pressure control, the average decline speed of casing pressure before the first gas production peak is $0.01 \mathrm{MPa} / \mathrm{d}$, the decrease rate of casing pressure is comparatively fast. The occurrence time of first gas production peak was generally about 450 days after drainage. In the meantime, the gas yield vary considerably and stability is rather poor. The occurrence time of second gas production peak was generally about 1900 days after drainage, the variation scope of gas yield weakened markedly and stability were getting better. The period between the two peaks is low gas yield stage which last for 500 days to 1500 days.

Theoretically, the effect of gas production in double-peak curve is satisfactory, the gas yield can achieve to $1500 \mathrm{~m}^{3} / \mathrm{d}$ or more in stable production period, and this type of curve is one of the typical drainage curve in high gas yield wells. However, CBM wells of double-peak curve constitutes only about $12.2 \%$ in $49 \mathrm{CBM}$ wells, and it mainly distributed in regions of borehole distance less than 200m. Large well spacing will cause inter-well interference difficult to form, eventually, this hardly to form regional pressure drop.

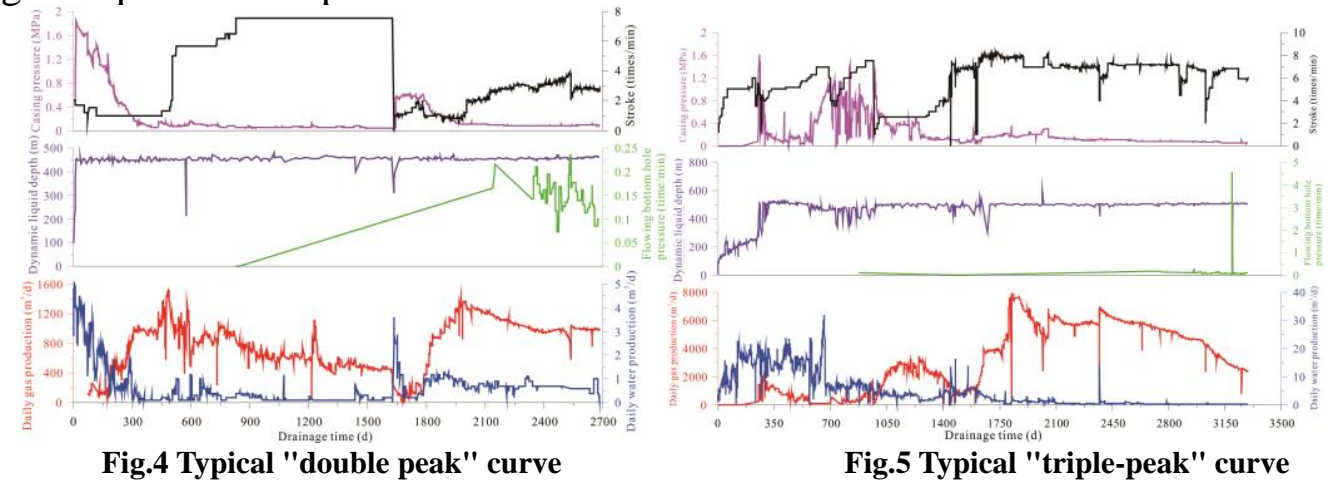

Triple-peak Curve. Triple-peak curve appear 3 times gas production peak in production process, and the three peaks increased gradually. The main reason for first peak is the free gas which desorbed by surrounding downdip older wells, and the first peak is low and of short duration owing to the low free gas content; the reason for the second peak is desorbed gas supplied by CBM wells, the second peak is higher than initial peak and of long duration owing to high gas content and high permeability; after the second peak, the gas production began to fall and last for 200 days, then the downdip CBM wells surrounding start desorbed, finally the two types of desorbed gas outputs together and formed the third gas production peak, the third peak is the highest and last a long time.

In the beginning, CBM wells produced a large amount of water and daily water production is about $15 \mathrm{~m}^{3} / \mathrm{d}$, this make free gas a breakthrough in water sealing zone. The peak maintain a short time due to limited free gas yield, and water production begin to decline; after water-discharging and pressure-dropping, it reaches the critical desorption pressure and begin to produce gas. Owing to the good coal reservoir physical property, CBM wells reaches the second gas production peak in 
about 1200 days and last a long time, with a peak of $3300 \mathrm{~m}^{3} / \mathrm{d}$; the casing pressure decreasing gradually and water production is almost $0 \mathrm{~m}^{3} / \mathrm{d}$, the gas production increases gradually and reaches peak in 1800 days, with a peak of $7918 \mathrm{~m}^{3} / \mathrm{d}$, this stage last for 800 days, after that, the gas production tail off. This type of curve is ideal CBM wells, the daily gas production is $3573.73 \mathrm{~m}^{3} / \mathrm{d}$, which is typical high-yield CBM wells. the small borehole distance cause inter-well interference easily and form common pressure drop funnel. With gas supply of surrounding CBM wells and good reservoir physical property(high gas content, high permeability), this type of CBM wells is the key object of study.

Linear Curve. The characteristics of linear curve(Fig.6) is almost nonexistent of stable gas production peak during gas generation. The whole curve shows less fluctuation, with daily gas production of $800 \mathrm{~m}^{3} / \mathrm{d}$ and daily water production of $1.57 \mathrm{~m}^{3} / \mathrm{d}$. According to corresponding location of CBM wells in drainage curve, this type of curve reflect the characteristic of destroyed reservoir and low gas content. The location of this type of CBM wells is in east-central poor gas region and northern structure developed area of Fanzhuang block. This type of CBM wells is near to faults and lead to decrease of gas content in coal reservoir. The coal body structure mainly develops coal of III or IV class, and it is unfit for CBM production. Linear curve account for $16.3 \%$ in 49 CBM wells.

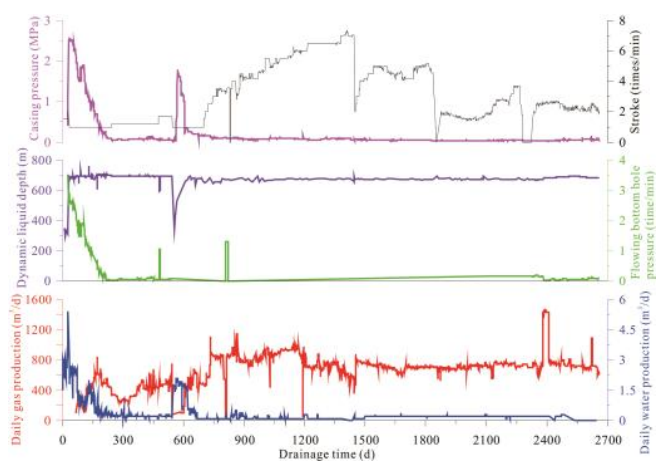

Fig.6 Typical "linear" curve

\section{Typical Index Analysis of Typical Drainage Curve}

According to the characteristics of CBM well gas production, the drainage curve is divided into 5 types. Through comparing and analysing the water production, pressure change characteristics and gas content of the 5 types of CBM wells, summed up the formation mechanism of typical drainage curve.

Table 1 data table of typical drainage curve

\begin{tabular}{|c|c|c|c|c|c|c|c|}
\hline \multirow[b]{2}{*}{$\begin{array}{l}\text { Well } \\
\text { Name }\end{array}$} & \multirow[b]{2}{*}{$\begin{array}{c}\text { Daily } \\
\text { average } \\
\text { gas } \\
\text { production } \\
\left(\mathrm{m}^{3} / \mathrm{d}\right)\end{array}$} & \multirow[b]{2}{*}{$\begin{array}{l}\text { Average } \\
\text { Maximum } \\
\text { daily gas } \\
\text { production } \\
\left(\mathrm{m}^{3} / \mathrm{d}\right)\end{array}$} & \multicolumn{2}{|c|}{$\begin{array}{l}\text { Geological } \\
\text { conditions }\end{array}$} & \multicolumn{3}{|c|}{ Engineering condition } \\
\hline & & & $\begin{array}{l}\text { Gas } \\
\text { conten } \\
\left(\mathrm{m}^{3} / \mathrm{t}\right)\end{array}$ & $\begin{array}{l}\text { Permeab } \\
\text { ility } \\
(\mathrm{mD})\end{array}$ & $\begin{array}{c}\text { Daily } \\
\text { average } \\
\text { water } \\
\text { yield } \\
\left(\mathrm{m}^{3} / \mathrm{d}\right)\end{array}$ & $\begin{array}{l}\text { Decline rate } \\
\text { of casing } \\
\text { pressure in } \\
\text { the early } \\
\text { stage } \\
(\mathrm{MPa} / \mathrm{d})\end{array}$ & $\begin{array}{c}\text { Distance } \\
\text { between } \\
\text { wells }(\mathrm{m})\end{array}$ \\
\hline $\begin{array}{l}\text { Single } \\
\text { peak type }\end{array}$ & 860.36 & 1836.77 & 20.23 & 0.95 & 1.65 & 0.0096 & 231.15 \\
\hline Step type & 1999.42 & 3330.52 & 20.05 & 1.06 & 3.03 & 0.0021 & 214.05 \\
\hline $\begin{array}{l}\text { Double } \\
\text { peak type }\end{array}$ & 1417.75 & 2505.33 & 18 & 1.21 & 1.17 & 0.0157 & 213.33 \\
\hline $\begin{array}{l}\text { Straight } \\
\text { line type }\end{array}$ & 839.13 & 2412.38 & 21.5 & 0.78 & 1.57 & 0.0046 & 216.75 \\
\hline $\begin{array}{l}\text { Triple } \\
\text { peak type }\end{array}$ & 3573.73 & 7918 & 23 & 1.5 & 4.67 & 0.0009 & 170 \\
\hline
\end{tabular}

As can be seen from the table 1, the triple peak type CBM wells had the highest daily gas production. From the analysis of geological conditions, both gas content and permeability affected CBM wells productivity. The higher gas content is and the better the permeability is, gas production of CBM wells will be higher. The gas content of single peak type and straight line type CBM wells 
were relatively higher, but the permeability were relatively lower. Due to the combined effect of gas content and permeability, the gas production were lower. Double peak type and step type gas content were relatively lower, but the permeability were relatively higher, so gas production were relatively higher.

From the analysis of engineering conditions, the casing pressure in early stage of Single peak type CBM wells fall fast, reaching gas production peak in a short time, then the gas production decreased gradually. A lot of CBM began to desorption near wells, resulted that the pressure drop funnel was too steep, the pressure couldn't be passed to the distant coal seams, which led to the shortage of gas supply. Pressure drop rate of step type CBM wells was the slowest, so the pressure drop funnel could be effectively extended, distal reservoir pressure could reduce to the critical desorption pressure and began to desorption, making step type CBM wells had a long stable production time, and the average daily gas production was the highest. The casing pressure in early stage of double peak type CBM wells fall so fast that it reached rapidly gas production peak in a short time. With the rapid desorption of coal seams in the near well area, gas production began to decline. Due to the high permeability of double peak type CBM wells, the distal reservoir began to desorption. After controlling the pressure drop velocity, the CBM wells once again reached the peak. The distance between wells of double peak type CBM wells were relatively smaller, which was easy to form inter-well interference and common pressure drop funnel. It had an important role for CBM wells to form gas production peak in the late stage. The average daily water yield and casing pressure drop speed of Straight line type CBM wells were controlled well, and the distance between wells were not too far. So engineering factor was not the reason of low gas production but was the low permeability. The distance between the "three peaks" coal bed methane well is only $170 \mathrm{~m}$, The distance between wells of triple peak type CBM wells was only $170 \mathrm{~m}$, which was easy to form inter-well interference and common pressure drop funnel. It had an important role for CBM wells to form gas production peak in the late stage. The pressure drop was very slow at the early stage, which was conducive to the expansion of pressure drop funnel. Most important of all, the gas supply around the declination of CBM wells made it show a special triple peak type, and later the peak of gas production lasted for a long time.

\section{Conclusions}

Based on the analysis of coal reservoir physical properties characteristics and 49 CBM Wells drainage curve in FanZhuang block, drawed the following conclusions:

The typical drainage curve is the external manifestation of the dynamic index of CBM wells production and the common coupling effects of geological factors and engineering factors. The higher gas content and permeability of CBM wells are, the higher the gas production is generally.

In the early stage, the decline rate of casing pressure is too high, the peak of gas production occurs in the short period and the duration is short. If the comprehensive physical properties characteristics of coal reservoir is not good, the drainage curve is generally single peak type. And if good, the curve is usually double peak type.

In the early stage, the decline rate of casing pressure is slow, initial gas production is lower, then the casing pressure gradually increased and the gas production also increased constantly. If the comprehensive physical properties characteristics of coal reservoir is good, the drainage curve is generally step type. And if not good, the curve is usually straight line type.

Triple peak type CBM wells, which forms by its good reservoir physical properties (including high gas content and high permeability), gas supply around the gas wells and the interference between wells, is a typical high production gas well.

\section{Acknowledgements}

Financial support for this work was provided by the National Major Research Program for Science and Technology of China (No. 2016ZX05044, No. 2016ZX05067, No. 2011ZX05061, No. 2011ZX05034), and the Fundamental Research Funds for the Central Universities of China(No. 


\section{Reference:}

[1] Ni, X.M., Chen, P., Zhu, M.Y.. 2010. Analysis of the main geological factors of coal bed methane vertical well productivity. Coal science and technology.07,109-113.

[2] Ni, X.M., Chen, P., Li, G.S., et al.. 2010. Relationship between coal structure and coalbed methane vertical well productivity in Encun coalfield.Natural Gas Geoscience.03,508-512.

[3] Wang, R., Dong, F., Meng, Z.P., et al.. 2014. Control mechanism of structure on coalbed methane well productivity in Fanzhuang block. Journal of China University of Mining and Technology.06,1025-1030.

[4] Ni, X.M., Su, X.B., Wei, Q.X., et al.. 2009. Relationship between coal reservoir permeability and coalbed methane vertical wells drainage curve. Journal of China coal society.09,1194-1198.

[5] Yang, X.C., Jie, M.X., Wang, G.J.. 2008. Analysis of the influence factors of production capacity in Pan River coalbed methane test area. Natural gas industry.03,99-101+147.

[6] Chen, T.G., Guan, Z.C.. 2006. Theory and technology of drilling engineering. Petroleum University Press.

[7] Chen, F., Li, Q.. 2006. Study on the damage of fracturing fluid. Natural gas industry. 01,109-111+168.

[8] Zhang, S.B., Su, X.B., Guo, H.Y., et al.. 2014. Damage and control of fracture flow conductivity in coalbed methane well drainage process. Journal of coal science.01,124-128.

[9] Tao S., Tang DZ., Xu H., et al.,2014. Factors controlling high-yield coalbed methane vertical wells in the Fanzhuang block,Southern Qinshui basin. International Journal of coal geology. 134-135, 38-45.

[10] Kang, Y.S., Qin, S.F., Han, J., et al.. 2013. Dynamic typical index analysis method system of coalbed methane well drainage. Journal of China coal society.10,1825-1830.

[11] Luo, Z.X., Li, T.J., Guo, D.L., et al.. 2012. Type classification and factor analysis of coalbed methane drainage curve. Journal of Chongqing University of Science and Technology (NATURAL SCIENCE EDITION).04,56-59.

[12] Hu, Q.J., Li, M.X., Wang, L.L., et al. 2012. Analysis of gas production curve characteristics of coalbed methane vertical well in Fanzhuang block. China coalbed methane.06,3-7.

[13] Li, M.X., Zhang, C., Zhang, S.X., et al. 2012. Coalbed methane vertical wells drainage characteristics in Fanzhuang block of Qinshui Basin. China coalbed methane.03,3-7. 